\title{
Postsurgical Orthodontic Treatment Planning: a Case Report with 20 Years Follow-up
}

\author{
Giampietro Farronato $^{1}$, Umberto Garagiola ${ }^{1}$, Vera Carletti ${ }^{1}$, Paolo Cressoni ${ }^{1}$, Carmen Mortellaro ${ }^{2}$ \\ ${ }^{1}$ Department of Orthodontics, University of Milan, Fondazione IRCCS Cà Granda, Ospedale Maggiore Policlinico, Milan, \\ Italy. \\ ${ }^{2}$ Division of Oral Maxillofacial Surgery, Department of Oral Medicine and Diagnostic Sciences, University of Eastern \\ Piedmont Novara, Novara, Italy.
}

\author{
Corresponding Author: \\ Giampietro Farronato \\ Department of Orthodontics \\ University of Milan \\ Fondazione IRCCS Cà Granda, Ospedale Maggiore Policlinico \\ Via Della Commenda 10, Milan 20122 \\ Italy \\ Phone: +0039255032520 \\ Fax: +0039250320239 \\ E-mail: giampietro.farronato@unimi.it
}

\begin{abstract}
Background: Traditionally, maxillofacial deformities are corrected surgically after an initial orthodontic treatment phase. However, in this article, the authors emphasize the postsurgical therapeutic protocol which is extremely important for determining the final and permanent retention of the corrected occlusion.

Methods: A 55 year old female with severe skeletal Class II malocclusion is presented. Combined surgical and orthodontic correction of the malocclusion was used.

Results: The step-by-step procedure the authors followed for the postsurgical therapy is described. The goals of the postoperative therapy were to restore and rehabilitate neuromuscular function, obtain occlusal stabilization, grind teeth selectively, and final occlusion retention. The importance of a surgical occlusal splint for rehabilitating stomatognathic neuromuscular function postoperatively was demonstrated. Furthermore, the orthodontic-prosthodontic treatment ensured occlusion stability after the surgical correction. The long-term results confirmed the efficacy of the treatment protocol presented here from both functional and aesthetical perspectives.

Conclusions: Postsurgical orthodontic treatment is an important step in the surgical and orthodontic therapy of maxillofacial deformities.
\end{abstract}

Keywords: dental occlusion; malocclusion; orthodontics, corrective; occlusal splints; maxillofacial orthognathic surgery; orthognathic surgical procedures.

Accepted for publication: 14 April 2011

To cite this article:

Farronato G, Garagiola U, Carletti V, Cressoni P, Mortellaro C. Postsurgical Orthodontic Treatment Planning: a Case Report with 20 Years Follow-up.

J Oral Maxillofac Res 2011 (Apr-Jun);2(2):e4

URL: http://www.ejomr.org/JOMR/archives/2011/2/e4/v2n2e4ht.pdf

doi: $10.5037 /$ jomr.2011.2204 


\section{INTRODUCTION}

Surgical-orthodontic treatment is universally recognized as the best therapeutic option for the adult patient with maxillofacial disharmony from both dental and skeletal perspectives [1]. This treatment is organized into four phases: presurgical orthodontic therapy, orthognathic surgery, postsurgical orthodontic therapy, and retention $[2,3]$. All of these steps are important for the success of orthognathic surgery, but this article focuses primarily on the postsurgical phase.

Goals of the postsurgical therapy are surgical fixation, restoration and rehabilitation of neuromuscular function, occlusal stabilization, selective grinding of teeth and final occlusion retention. The postsurgical phase has to achieve the restoration of a good neuromuscular function through a progressive reprogramming of the muscular and dental periodontal proprioception adequate to the new spatial situation of the maxillary and mandibular skeletal bases [4].

Final orthodontic and prosthodontic treatment permits correct occlusion, which will be stabilized by a good spatial jaw relationship, correct neuromuscular function, and parafunction prevention. It is evident that after surgical jaws correction, the adaptive changes in the orofacial complex contribute to causing relapse [4]. The occlusion should be as stable and optimal as possible to eliminate the reasons for relapse.

In this article, the authors underline the importance of postsurgical orthodontic treatment in the combined surgical-orthodontic therapy of maxillofacial deformities.

\section{Postsurgical treatment phases}

The approach presented here is characterized by the exact order of the various therapeutic phases, and this sequence is strictly related to goals of the postsurgical orthodontic treatment. These goals are postsurgical retention, restoration and rehabilitation of oral function, occlusal stabilization, retention, and selective grinding of teeth [5-8].

Postsurgical retention is carried out with intermaxillary fixation, and is kept in place for about 21 days (Figure $1 \mathrm{~A}$ ). The restoration of function begins after removing the intermaxillary fixation. An occlusal splint is fixed to the orthodontic arch with ligature wires and the patient begins to open and close his or her mouth using the indentations present in the splint as guides. For the first few days, the width of the mouth opening is obviously reduced as a consequence of immobilization and the new occlusal position with a different skeletal orientation and the consequent alteration in dental, skeletal, and muscular proprioceptive receptors. After 2 weeks, the patient usually opens his mouth wide enough, following the muscular reprogramming carried out under the guidance of the occlusal splint (Figure $1 \mathrm{~B}$ ). When oral function is restored sufficiently, the function is rehabilitated with a modification of the occlusal splint; lateral disclusive and protrusive excursion guides are created to perfect the dynamic jaw movements. During this phase, the occlusal splint can be cut distally at the canines to avoid any dental interference in the posterolateral sectors. All the dental elements must have brackets tied to a fixed appliance to avoid unwanted extrusion, except when this is specifically required by the treatment plan. The patient is asked to perform opening and closing, lateral and protrusive exercises three times a day (Figures $1 \mathrm{C}$ and $1 \mathrm{D}$ ).

After 3 to 4 weeks, good functional rehabilitation is obtained, permitting the removal of the occlusal splint and progression to the final occlusal stabilization. This principally involves postsurgical orthodontic treatment aimed at completing the occlusion retention obtained after surgery. Once the occlusal splint is removed, one must check to see if any gross prematurities or occlusal interference occur. These must be removed immediately, because the occlusion and function must be kept stable. First, the passive archwires must be removed and the position of the brackets revised as needed to optimize the subsequent treatment. Because the occlusal conditions have changed, new strategic position of the brackets aimed at obtaining the final occlusal relationship often becomes important. Thus, active archwires are used in relationship to the necessary dental movements. The completion of the treatment does not differ from that of any other traditional orthodontic therapy. In this phase, the maintenance of good periodontal conditions becomes particularly important. This contributes to the stability of the final result. During the final orthodontic phase, it may be necessary to modify the temporary restorations prepared preoperatively in view of the planned final occlusion. It may also be necessary to prepare another prosthesis to restore compromised dental elements. The postsurgical orthodontic phase lasts about 6 months (Figure $1 \mathrm{E}$ ). When the orthodontic appliance is removed, the retention phase, which lasts 4 to 6 months, follows. Preference is given to the use of a gnathologic positioner as the best instrument to maintain the achieved results and to improve them if necessary; this is obtained from the occlusal information incorporated in the setup of the positioner.

The patient is instructed to use the positioner for $4 \mathrm{~h}$ during the day and all night. After about 6 months, the daytime use of the positioner is suspended, the device is lightened and made passive, and the patient is advised to use it during the night as protection against possible parafunctions that could nullify the result with time. 

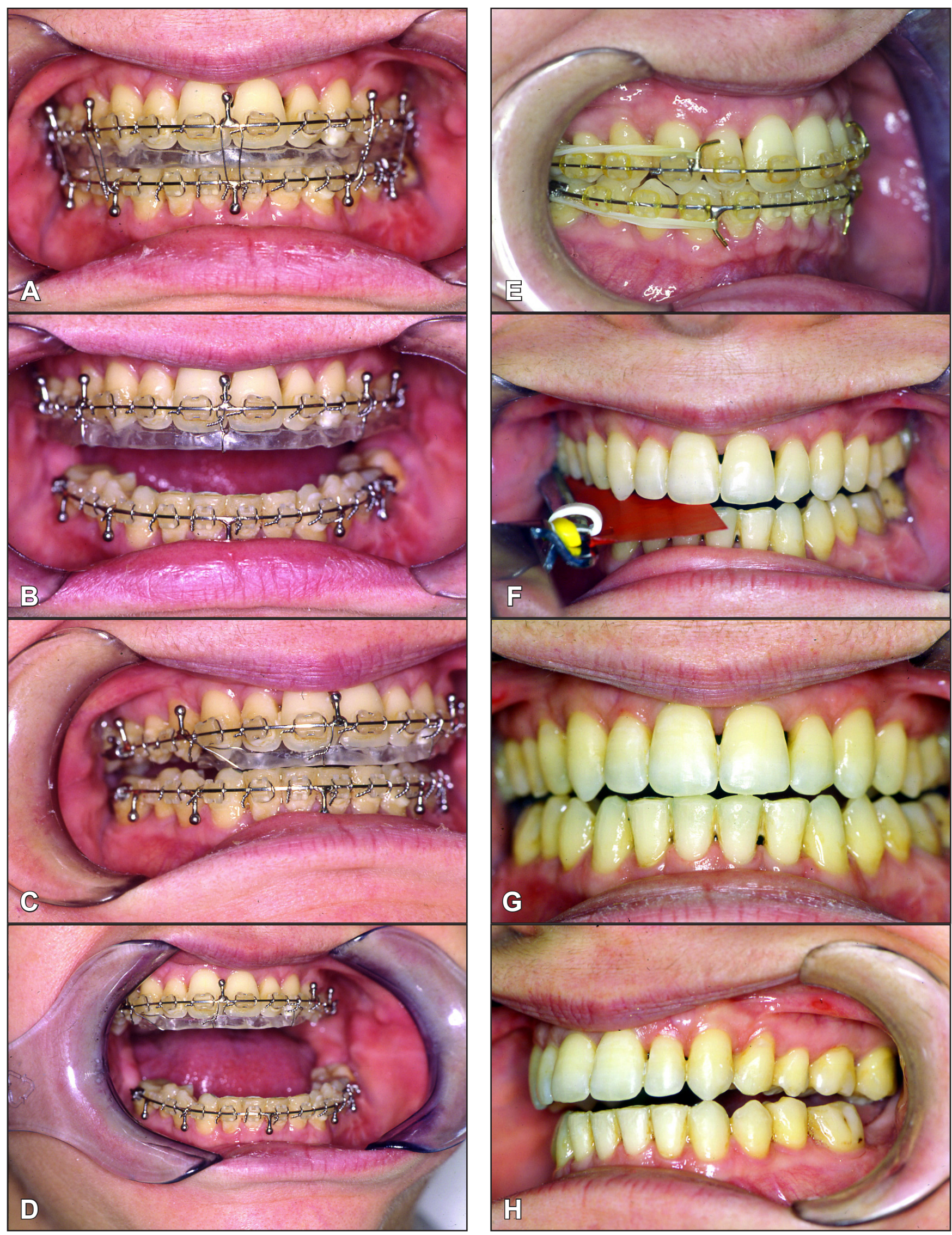

Figure 1. A = postsurgical intermaxillary fixation;

$\mathrm{B}=$ mouth opening width on removal of the intermaxillary fixation;

$\mathrm{C}$ and $\mathrm{D}=$ function rehabilitation with the modification of the occlusal splint;

$\mathrm{E}=$ occlusal stabilization;

$\mathrm{F}, \mathrm{G}$ and $\mathrm{H}=$ selective grinding of teeth to finalize the occlusion. 
At the beginning of the retention phase and at periodical checkups, the patient undergoes selective occlusal grinding to stabilise the centric position and to remove any prematurities or interferences with the centric and eccentric movements (Figures $1 \mathrm{~F}$ to $1 \mathrm{H}$ ). The selective grinding of teeth is used to obtain a centered mandibular position, with bilateral stopping contacts, with coincidence between centric relation and centric occlusion. Concerning the mandibular dynamics, the authors preferably look for disclusive canine guidance in the lateral movements and incisor guidance in the protrusive movements, according to the traditional teachings on occlusion. The authors firmly believe that any prematurities or dislocating interference or the development of daytime or nighttime parafunctions are the most frequent causes of relapse from the result achieved at the end of active treatment $[\underline{4}, \underline{9}, \underline{10}]$.

\section{CASE DESCRIPTION AND RESULTS}

A 55 year old female patient applied to the Department of Orthodontics, University of Milan, Fondazione

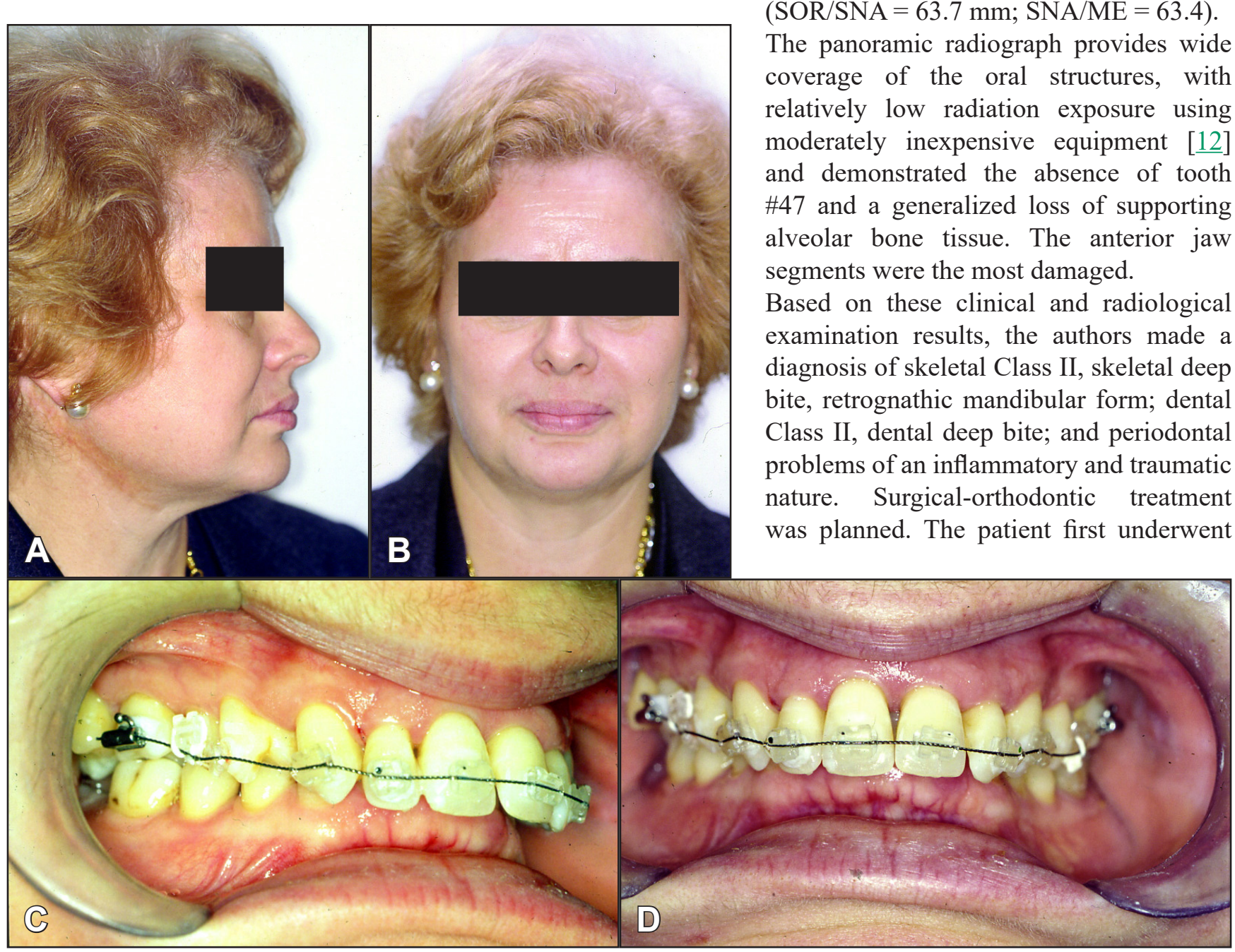

IRCCS Cà Granda, Ospedale Maggiore Policlinico, Milan, Italy, because she noticed that her teeth were becoming mobile. The patient had been treated in the past for periodontal problems, but had recently noticed a serious worsening of her dental health. The oral cavity examination revealed a serious Class II malocclusion with a substantial increase in the incisor overjet $(11 \mathrm{~mm})$ and overbite $(8 \mathrm{~mm})$. A wire splint was fixed on the maxillary front teeth; periodontal pockets and increased dental mobility were clearly noticeable for most of the teeth in both dental arches. The patient suffered from a temporomandibular joint (TMJ) dysfunction syndrome, a symptom complex consisting of pain, masticatory muscle tenderness, difficult chewing, clicking in the joint, limitation or alteration of mandibular movement, and cervical pain and headache associated to otovestibular symptoms (Figures $2 \mathrm{~A}$ to $2 \mathrm{H}$ ).

The lateral cephalometric radiograph showed a skeletal Class II malocclusion with mandibular retrognathism according to the classification of Giannì [11] (SNA = 81.8; $\mathrm{SNB}=76.1$; $\mathrm{ANB}=5.7)$; the anterior skeletal vertical dimension was reduced by about $5.5 \mathrm{~mm}$ $(\mathrm{SOR} / \mathrm{SNA}=63.7 \mathrm{~mm} ; \mathrm{SNA} / \mathrm{ME}=63.4)$.

The panoramic radiograph provides wide coverage of the oral structures, with relatively low radiation exposure using moderately inexpensive equipment [12] and demonstrated the absence of tooth \#47 and a generalized loss of supporting alveolar bone tissue. The anterior jaw segments were the most damaged.

Based on these clinical and radiological examination results, the authors made a diagnosis of skeletal Class II, skeletal deep bite, retrognathic mandibular form; dental Class II, dental deep bite; and periodontal problems of an inflammatory and traumatic nature. Surgical-orthodontic treatment was planned. The patient first underwent

Figure 2. A, B, C and D = pretreatment facial and intraoral photographs. 
initial periodontal preparation lasting 6 months, and then fixed appliances were bonded to the dental arches to make them suitable for the planned operation, which consisted of mandibular advancement and clockwise mandibular rotation to correct the skeletal Class II and skeletal deep bite. During presurgical phase (14 months), dental interferences were eliminated and the real discrepancy between skeletal jaw and mandible was restored.

The most important aims of the orthodontic treatment before surgery were dental alignment to eliminate ill-positioning and

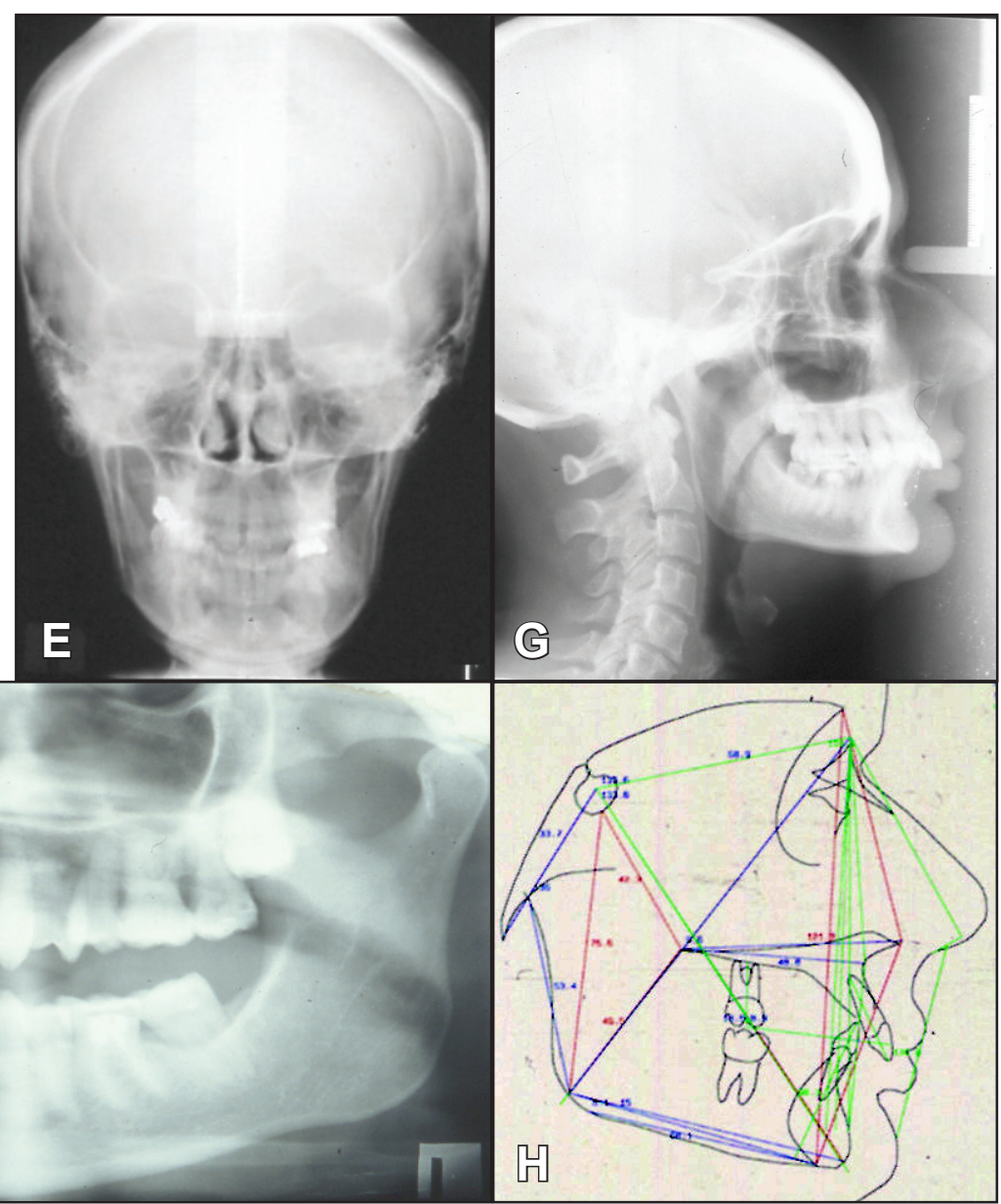

Figure 2. E, F, G and $\mathrm{H}=$ pretreatment posteroanterior, panoramic radiographs; lateral cephalometric radiograph and tracing before treatment.
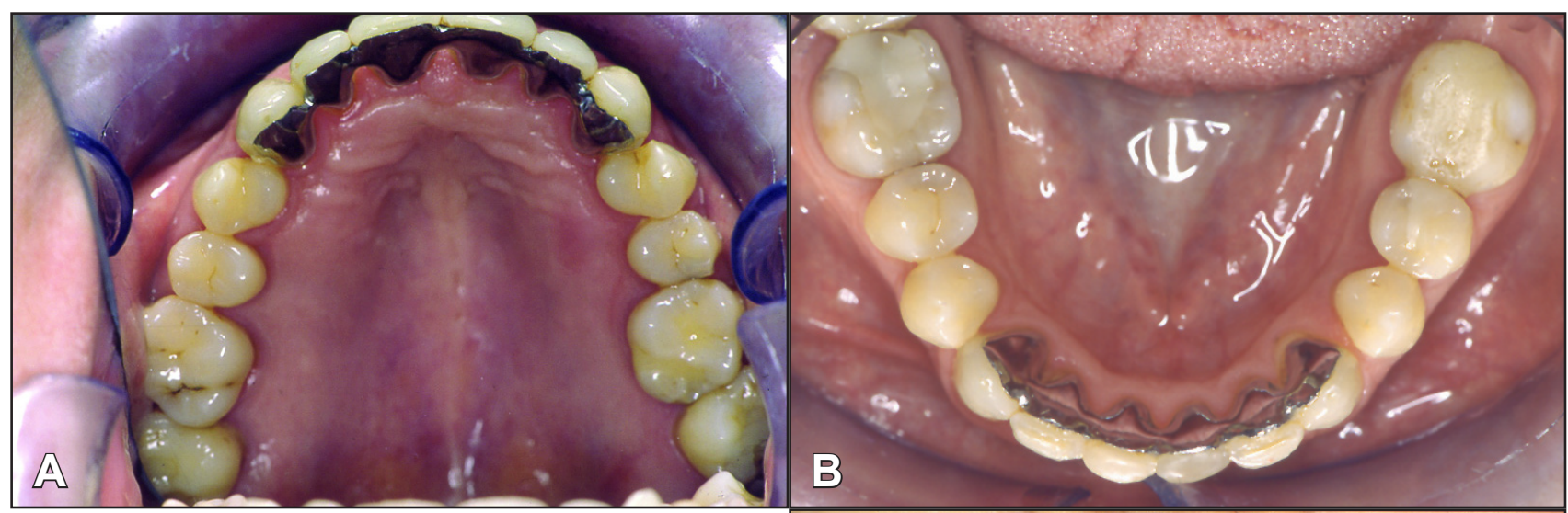

dental crowding, dental-alveolar decompensation to eliminate dental compensation by forward inclination of the anterior-inferior teeth and backward inclination of anterior maxillary teeth, pointing out the real extent of the sagittal skeletal defect, and the alignment of the dental arches, in their final position, matching them together perfectly.

The surgery, performed in 1990, consisted of a bilateral mandibular advancement of $10 \mathrm{~mm}$ and rigid fixing plates by a bilateral sagittal Obwegeser-Dal Pont osteotomy. The diagnosis determined where to operate

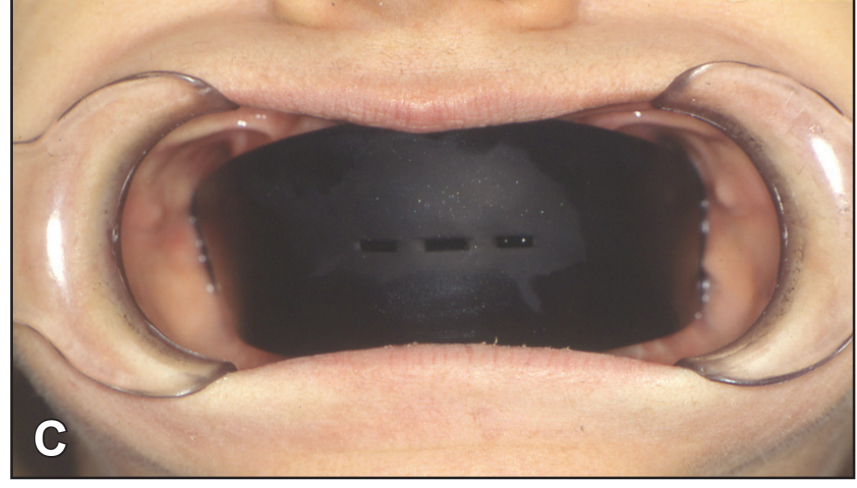

Figure 3. A, B and $\mathrm{C}=$ retention phase. 
and gave information on the vectorial directions of the surgical movements of the bones to correct the skeletal vertical dimension. The sagittal shifts corrected the skeletal Class II. The clockwise rotation of the mandible realized the correction of the skeletal deep bite.

Postoperatively, the jaws were fixed for 4 weeks using intermaxillary fixation.

After postsurgical retention using intermaxillary fixation, the restoration phase began and oral function was subsequently rehabilitated with an occlusal splint using our protocol (Figures $1 \mathrm{~A}$ to $1 \mathrm{H}$ ). The postoperative orthodontic treatment lasted 6 months, and optimized the dental intercuspidation, using intermaxillary elastics.

Occlusal stabilization followed to complete the postsurgical orthodontic phase. Before removing the archwires, two Maryland-type periodontal splints were applied to the anterior segments of both arches. A positioner was used to maintain the results of surgicalorthodontic treatment. The patient subsequently underwent selective grinding to finalize the occlusion and maintain stability (Figures $3 \mathrm{~A}$ to $3 \mathrm{C}$ ).

The posttreatment cephalometric radiograph showed skeletal Class I $(\mathrm{ANB}=3.3)$ according to Giannì [11]
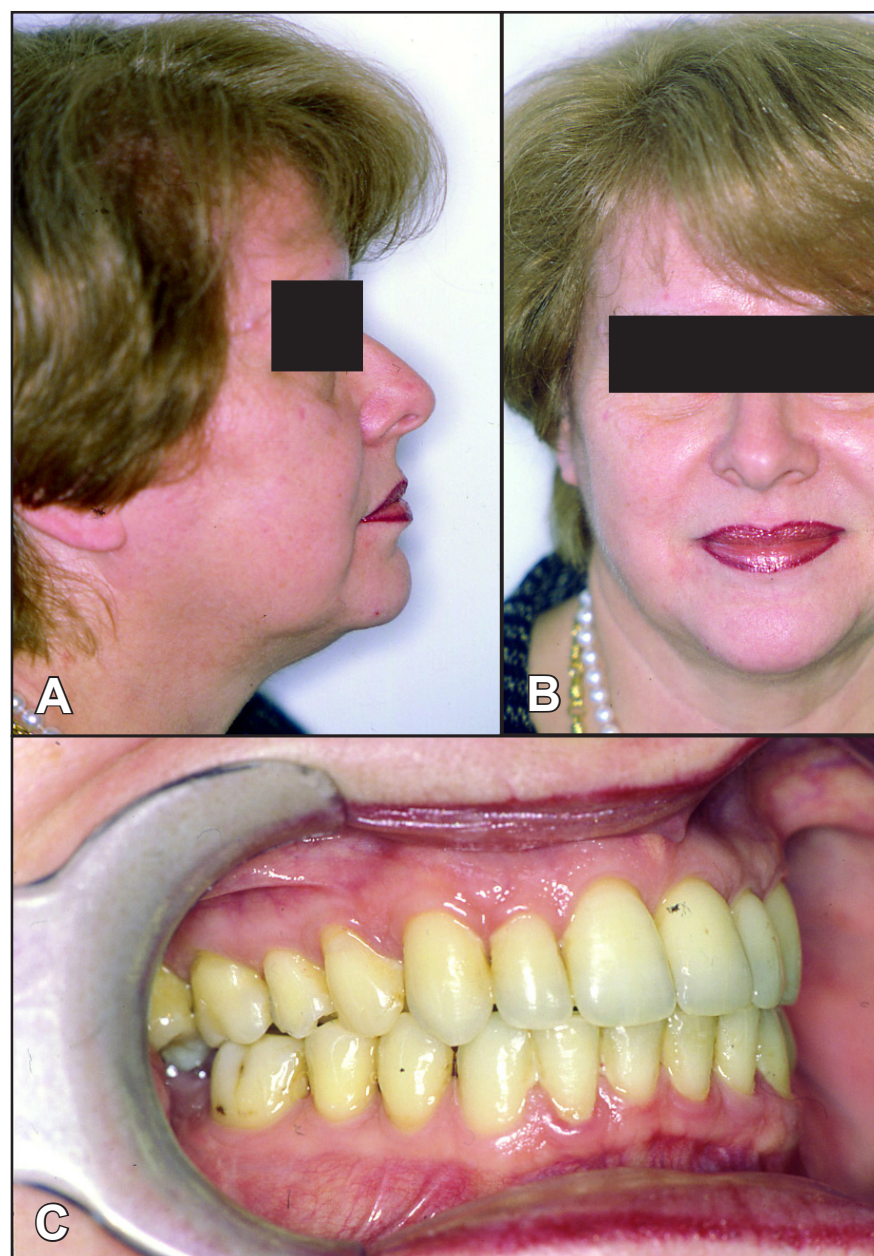

with restoration of the correct anterior skeletal vertical dimension. The panoramic radiograph showed maintenance or improvement of the periodontal condition present at the beginning of treatment (Figures $4 \mathrm{~A}$ to $4 \mathrm{H}$ ).

All of the craniomandibular disorders were reduced significantly, especially the muscular spasms and headache. The final electromyographic examination showed qualitative and quantitative improvement in the temporal and masseter muscles.

Long-term clinical follow-up (20 years) has confirmed the results (Figures $5 \mathrm{~A}$ to $5 \mathrm{D}$ ).

\section{DISCUSSION}

For the surgical treatment of mandible deformities, the authors prefer non-rigid fixation techniques. The authors are aware that rigid fixation has some indisputable advantages, especially greater comfort for the patient in the postsurgical phase; it also has negative aspects that do not favour its indiscriminate use [13]. We believe that the greatest limitation of rigid fixation is the need for an absolutely precise surgical technique, particularly when positioning the proximal segment of the osteotomized mandible. Rigid fixation also increases the risk of condylar rotation with distraction when the proximal segment is fixed to the distal segment rigidly [14-16]. We attribute many of the relapses seen in orthognathic surgery to the fact that repositioning of the skeletal bases takes place in a spatial situation that is not compatible with the limits of the patient's neuromuscular tolerance, and not to incorrect procedures or inaccurate techniques. If the position of the jaws is not in harmony with the function of the neuromuscular system, it does not work to stabilise the surgical result, but has a negative effect, creating a basis for

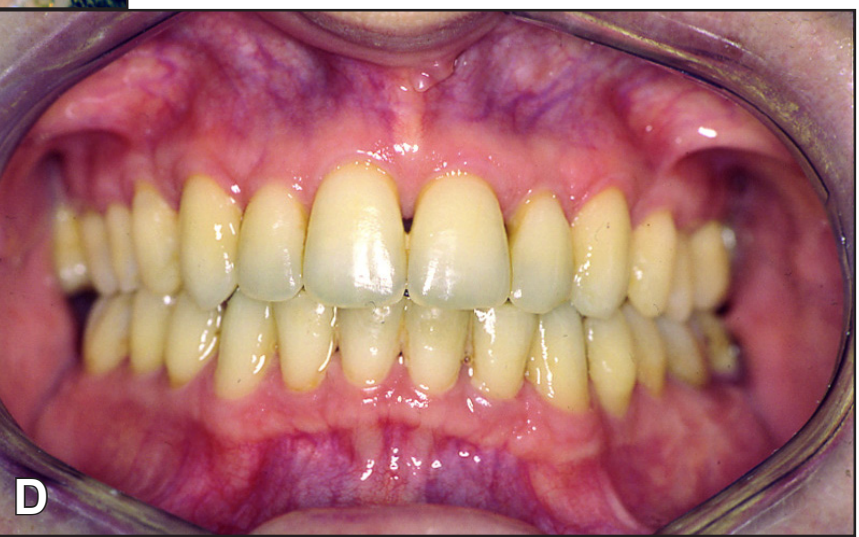

Figure 4. A, B, C and D = posttreatment facial and intraoral photographs. 
relapse [17-19].

The incidence of TMJ pain and dysfunction in adults appears to differ among studies. Malocclusion is one of the suggested etiological factors in internal derangements of the TMJ [20], whereas maxillomandibular relationship disharmony formed the basis of most of the early theories of the etiology of "TMJ syndrome" [21]. The correction of discrepancies in occlusion and maxillomandibular relationship by orthognathic surgery should improve TMJ function $[22,23]$. Although some authors $[24,25]$ advocate orthognathic surgery in cases with TMJ
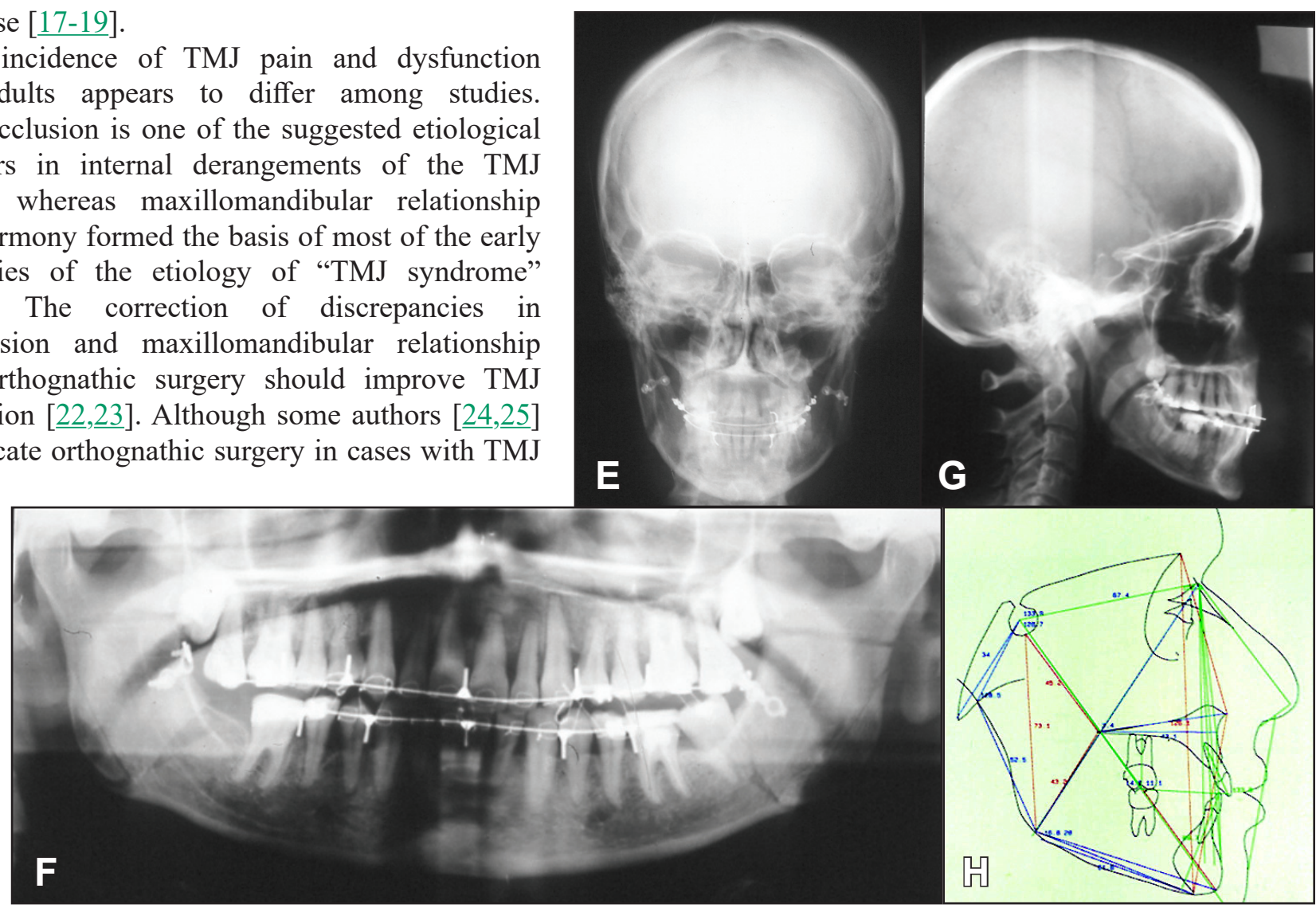

Figure 4. E, F, G and $\mathrm{H}=$ posttreatment posteroanterior, panoramic radiographs; lateral cephalometric radiograph and tracing after treatment.

symptoms in combination with dysgnathia, it is still unclear whether there is any association between these two phenomena $[21,26]$. Conversely, orthognathic surgery can produce TMJ symptoms by changing the position of the mandible and maxilla relative to each other and consequently the position of the condyle in the glenoid fossa $[27,28]$. Mandibular ramus osteotomies will influence this position directly [29], whereas the influence in maxillary

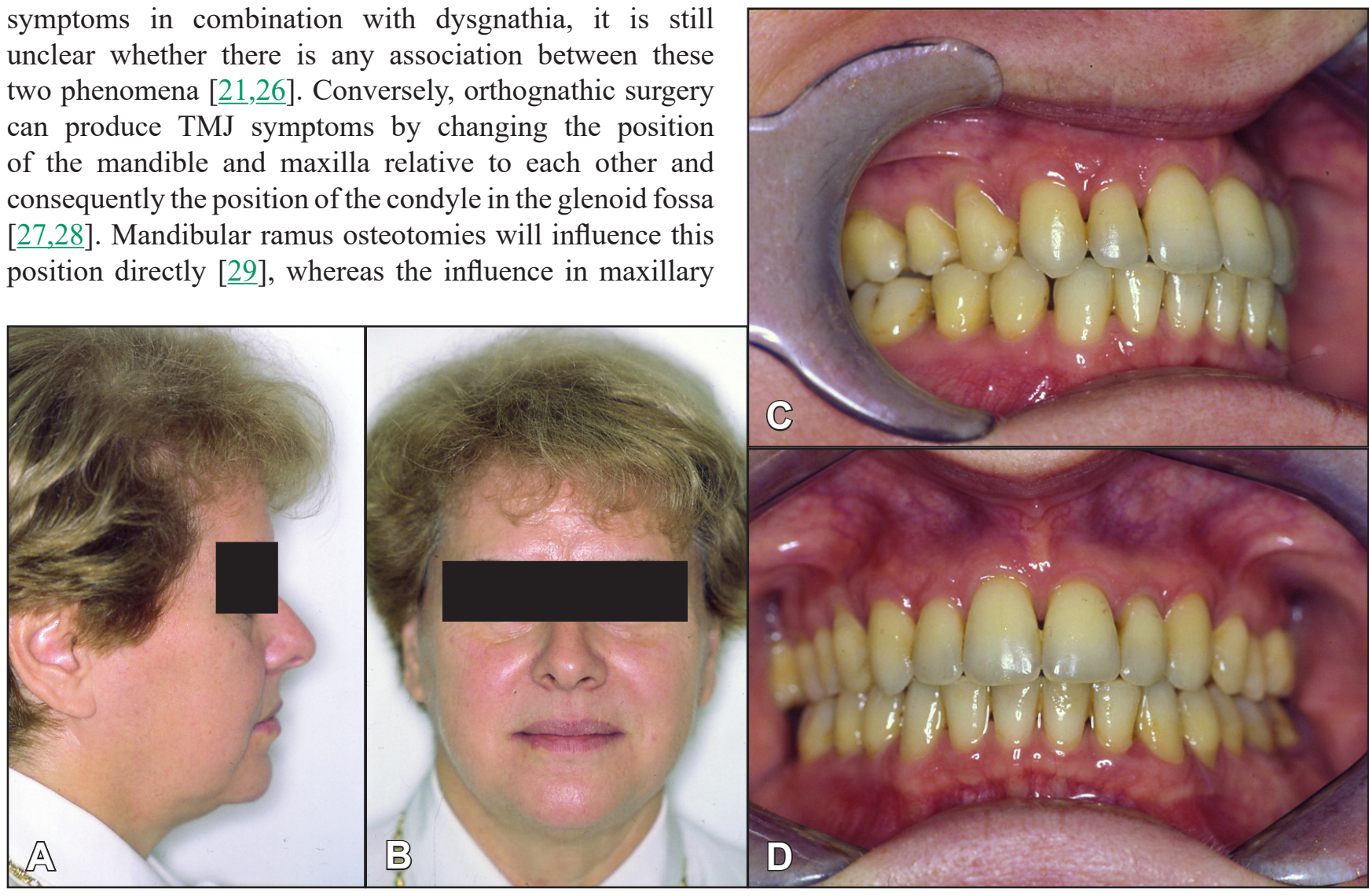

Figure 5. A, B, C and D = posttreatment facial and intraoral photographs after twenty years. 
osteotomies will be indirect, because of autorotation $[\underline{30}, \underline{31}]$.

Because compliance of the neuromuscular system is difficult to predict in each patient, the use of a method that requires a predetermined final skeletal position without the possibility for successive adjustments represents a risk that must be examined carefully. The authors prefer to use surgical techniques that do not result in the complete detachment of the mandibular muscles, and prefer to fix the mandibular segments using wire osteosynthesis or mini-plates for their uniting action only, without the use of transcortical screws or other extremely rigid systems. Postoperatively, the muscles serve to keep the proximal segment of the mandible in the correct condylar relationship and callus formation may be influenced by the neuromuscular response of the patient as soon as the stomatognathic function returns to normal [32].

The goal of presurgical orthodontics is to position the teeth, allowing an optimal surgical correction of the jawbones. While intra-arch alignment is similar to conventional orthodontics, leveling is not carried out automatically in surgical patients. In open-bite cases, steps within the arches are an indication for segmental surgery. Orthodontic leveling will be limited to the segments, and segments will be leveled with differential intrusion at surgery. In deep-bite/short-face patients, as in this case report, leveling a severe curve of Spee should be done after surgery. Anteroposteriorly, dental compensations are removed by ideally positioning the teeth relative to their skeletal bases. This will make the malocclusion look worse presurgically, but it will show the true entity of the skeletal problem, thus facilitating an optimal surgery [33]. It is important to recognize if a transverse problem is skeletal or dental and if the treatment should be done orthodontically, by segmental surgery, or by surgically assisted palatal expansion. Postsurgical orthodontics will bring teeth into correct position and proper intercuspation within a reasonable time period $[\underline{32}, \underline{33}]$.

\section{CONCLUSIONS}

In surgical-orthodontic treatment, the correct control of the postsurgical orthodontic phase is as important as the presurgical orthodontic phase. A good final result depends not only on the initial diagnosis, but also on the exact planning and execution of the orthognathic surgery. Postoperative orthodontic therapy is used to finalize and perfect the dental occlusion relative to the new skeletal relationships. In the postsurgical phase, it is important to restore neuromuscular function through progressive reprogramming of muscular and dental-periodontal proprioception that is adequate for the new spatial situation of the maxillary and mandibular skeletal bases. Finally, the orthodontic and prosthodontic treatment permits correct occlusion, which will be stabilized by a good spatial jaw relationship, correct neuromuscular function, and the prevention of parafunction. Aesthetics, function, stability, and treatment time have to be considered for the decision-making process.

The therapeutic treatment of these serious anomalies must be neither orthodontic nor surgical alone. Orthognathic surgery is important when it is considered as part of the therapeutic method. A different treatment approach leads to poorer functionality, and the problem of a relapse.

\section{ACKNOWLEDGMENT AND DISCLOSURE STATEMENTS}

The authors report no conflicts of interest related to this study. No external funding, apart from the support of the authors' institution, was available for this study.

\section{REFERENCES}

1. Farronato G, Maspero C, Giannini L, Farronato D. Occlusal splint guides for presurgical orthodontic treatment. J Clin Orthod. 2008 Sep;42(9):508-12. [Medline: 18974457]

2. Busby BR, Bailey LJ, Proffit WR, Phillips C, White RP Jr. Long-term stability of surgical class III treatment: a study of 5-year postsurgical results. Int J Adult Orthodon Orthognath Surg. 2002 Fall;17(3):159-70. [Medline: 12353934]

3. Jacobs JD, Sinclair PM. Principles of orthodontic mechanics in orthognathic surgery cases. Am J Orthod. 1983 Nov;84(5):399-407. [Medline: 6579841] [doi: 10.1016/0002-9416(93)90003-P]

4. Proffit WR, Turvey TA, Phillips C. Orthognathic surgery: a hierarchy of stability. Int J Adult Orthodon Orthognath Surg. 1996;11(3):191-204. [Medline: 9456622]

5. Lee RT. A splint for immediate surgical orthognathic fixation and release during orthodontic treatment. Eur J Orthod. 1991 Jun;13(3):209-11. [Medline: 1936139]

6. Bailey LJ, Cevidanes LH, Proffit WR. Stability and predictability of orthognathic surgery. Am J Orthod Dentofacial Orthop. 2004 Sep;126(3):273-7. [Medline: 15356484] [doi: 10.1016/j.ajodo.2004.06.003] 
7. Proffit WR, Bailey LJ, Phillips C, Turvey TA. Long-term stability of surgical open-bite correction by Le Fort I osteotomy. Angle Orthod. 2000 Apr;70(2):112-7. [Medline: 10832998] [FREE Full Text]

8. Ueki K, Marukawa K, Shimada M, Nakagawa K, Yamamoto E, Niizawa S. Changes in the chewing path of patients in skeletal class III with and without asymmetry before and after orthognathic surgery. J Oral Maxillofac Surg. 2005 Apr;63(4):442-8. [Medline: 15789314] [doi: 10.1016/j.joms.2004.06.059]

9. Wolford LM, Reiche-Fischel O, Mehra P. Changes in temporomandibular joint dysfunction after orthognathic surgery. J Oral Maxillofac Surg. 2003 Jun;61(6):655-60; discussion 661. [Medline: 12796870] [doi:10.1053/joms.2003.50131]

10. van den Braber W, van der Bilt A, van der Glas H, Rosenberg T, Koole R. The influence of mandibular advancement surgery on oral function in retrognathic patients: a 5-year follow-up study. J Oral Maxillofac Surg. 2006 Aug;64(8):1237-40. [Medline: 16860216] [doi: 10.1016/j.joms.2006.04.019]

11. Giannì E, Sala G, Farronato GP, Candini G, Anselmi M. [Orthognathic surgical therapy. 3. Psychological problems]. Mondo Ortod. 1988 May-Jun;13(3):47-55. [Article in Italian] [Medline: 3256789]

12. Juodzbalys G, Wang HL. Guidelines for the Identification of the Mandibular Vital Structures: Practical Clinical Applications of Anatomy and Radiological Examination Methods. J Oral Maxillofac Res 2010;1(2):e1. [URL: http://www.ejomr.org/JOMR/archives/2010/2/e1/e1ht.pdf] [doi: 10.5037/jomr.2010.1201]

13. Perrott DH, Lu YF, Pogrel MA, Kaban LB. Stability of sagittal split osteotomies. A comparison of three stabilization techniques. Oral Surg Oral Med Oral Pathol. 1994 Dec;78(6):696-704. [Medline: 7898905] [doi: 10.1016/0030-4220(94)90083-3]

14. Kundert M, Hadjianghelou $\mathrm{O}$. Condylar displacement after sagittal splitting of the mandibular rami. A short-term radiographic study. J Maxillofac Surg. 1980 Nov;8(4):278-87. [Medline: 6936510] [doi: 10.1016/S0301-0503(80)80115-9]

15. Gerressen M, Zadeh MD, Stockbrink G, Riediger D, Ghassemi A. The functional long-term results after bilateral sagittal split osteotomy (BSSO) with and without a condylar positioning device. J Oral Maxillofac Surg. 2006 Nov;64(11):1624-30. [Medline: 17052588] [doi: $10.1016 /$ j.joms.2005.11.110]

16. Oguri Y, Yamada K, Fukui T, Hanada K, Kohno S. Mandibular movement and frontal craniofacial morphology in orthognathic surgery patients with mandibular deviation and protrusion. J Oral Rehabil. 2003 Apr;30(4):392-400. [Medline: 12631163] [doi: 10.1046/j.1365-2842.2003.01040.x]

17. Eckhardt CE, Cunningham SJ. How predictable is orthognathic surgery? Eur J Orthod. 2004 Jun;26(3):303-9. [Medline: 15222716] [doi: 10.1093/ejo/26.3.303]

18. Swinnen K, Politis C, Willems G, De Bruyne I, Fieuws S, Heidbuchel K, van Erum R, Verdonck A, Carels C. Skeletal and dento-alveolar stability after surgical-orthodontic treatment of anterior open bite: a retrospective study. Eur J Orthod. 2001 Oct;23(5):547-57. [Medline: 11668874] [doi: 10.1093/ejo/23.5.547]

19. Fischer K, von Konow L, Brattström V. Open bite: stability after bimaxillary surgery--2-year treatment outcomes in 58 patients. Eur J Orthod. 2000 Dec;22(6):711-8. [Medline: 11212606] [FREE Full Text] [doi: 10.1093/ejo/22.6.711]

20. Dolwick MF, Katzberg RW, Helms CA. Internal derangements of the temporomandibular joint: fact or fiction? J Prosthet Dent. 1983 Mar;49(3):415-8. Review. [Medline: 6341552] [doi: 10.1016/0022-3913(83)90287-1]

21. Laskin D, Green C, Hylander W. TMD's: An Evidence-Based Approach to Diagnosis and Treatment. Quintessence Books, Chicago, 2006.

22. Mohlin B, Ingervall B, Thilander B. Relation between malocclusion and mandibular dysfunction in Swedish men. Eur J Orthod. 1980;2(4):229-38. [Medline: 6961042]

23. Wisth PJ. Mandibular function and dysfunction in patients with mandibular prognathism. Am J Orthod. 1984 Mar;85(3):193-8. [Medline: 6584030] [doi: 10.1016/0002-9416(84)90058-7]

24. Van Sickels JE, Ivey DW. Myofacial pain dysfunction: a manifestation of the short-face syndrome. J Prosthet Dent. 1979 Nov;42(5):547-50. [Medline: 290805] [doi: 10.1016/0022-3913(79)90252-X]

25. Piecuch J, Tideman H, DeKoomen H. Short-face syndrome: treatment of myofascial pain dysfunction by maxillary disimpaction. Oral Surg Oral Med Oral Pathol. 1980 Feb;49(2):112-6. [Medline: 6928280] [doi: 10.1016/0030-4220(80)90301-1]

26. Tucker MR, Thomas PM. Temporomandibular pain and dysfunction in the orthodontic surgical patient: rationale for evaluation and treatment sequencing. Int J Adult Orthodon Orthognath Surg. 1986 Winter;1(1):11-22. [Medline: 3457872]

27. Karabouta I, Martis C. The TMJ dysfunction syndrome before and after sagittal split osteotomy of the rami. J Maxillofac Surg. 1985 Aug;13(4):185-8. [Medline: 3860598] [doi: 10.1016/S0301-0503(85)80045-X]

28. Bouwman JP, Kerstens HC, Tuinzing DB. Condylar resorption in orthognathic surgery. The role of intermaxillary fixation. Oral Surg Oral Med Oral Pathol. 1994 Aug;78(2):138-41. [Medline: 7936579] [doi: 10.1016/0030-4220(94)90135-X]

29. Kerstens HC, Tuinzing DB, van der Kwast WA. Temporomandibular joint symptoms in orthognathic surgery. J Craniomaxillofac Surg. 1989 Jul;17(5):215-8. [Medline: 2788177] [doi: 10.1016/S1010-5182(89)80071-X]

30. O'Ryan F, Epker BN. Surgical orthodontics and the temporomandibular joint. II. Mandibular advancement via modified sagittal split ramus osteotomies. Am J Orthod. 1983 May;83(5):418-27. [Medline: 6573849] [doi: 10.1016/0002-9416(83)90325-1] 
31. Greebe RB, Tuinzing DB. Superior repositioning of the maxilla by a Le Fort I osteotomy: a review of 26 patients. Oral Surg Oral Med Oral Pathol. 1987 Feb;63(2):158-61. [Medline: 3469597] [doi: 10.1016/0030-4220(87)90304-5]

32. Garagiola U. Orthognathic surgery osseointegration and adult orthodontics: multidisciplinary synergy to correct dentofacial deformities. J of Japan Ass of Adult Orthodontics. 2003 June;10(1):17-26.

33. Sabri R. Orthodontic objectives in orthognathic surgery: state of the art today. World J Orthod. 2006 Summer;7(2):177-91. Review. [Medline: 16779977]

\section{To cite this article:}

Farronato G, Garagiola U, Carletti V, Cressoni P, Mortellaro C. Postsurgical Orthodontic Treatment Planning: a Case Report with 20 Years Follow-up.

J Oral Maxillofac Res 2011;2(2):e4

URL: http://www.ejomr.org/JOMR/archives/2011/2/e4/v2n2e4ht.pdf

doi: $10.5037 /$ jomr.2011.2204

Copyright ( $\odot$ Farronato G, Garagiola U, Carletti V, Cressoni P, Mortellaro C. Accepted for publication in the JOURNAL OF ORAL \& MAXILLOFACIAL RESEARCH (http://www.ejomr.org/), 14 April 2011.

This is an open-access article, first published in the JOURNAL OF ORAL \& MAXILLOFACIAL RESEARCH, distributed under the terms of the Creative Commons Attribution-Noncommercial-No Derivative Works 3.0 Unported License, which permits unrestricted non-commercial use, distribution, and reproduction in any medium, provided the original work and is properly cited. The copyright, license information and link to the original publication on (http://www.ejomr.org/) must be included. 